\title{
Nanohydroxyapatite-reinforced chitosan composite hydrogel for bone tissue repair in vitro and in vivo
}

\author{
S Dhivya', S Saravanan ${ }^{1}$, TP Sastry² and N Selvamurugan ${ }^{1 *}$
}

\begin{abstract}
Background: Bone loss during trauma, surgeries, and tumor resection often results in critical-sized bone defects that need to be filled with substitutionary materials. Complications associated with conventional grafting techniques have led to the development of bioactive tissue-engineered bone scaffolds. The potential application of hydrogels as three-dimensional (3D) matrices in tissue engineering has gained attention in recent years because of the superior sensitivity, injectability, and minimal invasive properties of hydrogels. Improvements in the bioactivity and mechanical strength of hydrogels can be achieved with the addition of ceramics. Based on the features required for bone regeneration, an injectable thermosensitive hydrogel containing zinc-doped chitosan/nanohydroxyapatite/betaglycerophosphate ( $\mathrm{n} n-\mathrm{CS} / \mathrm{nHAp} / \beta-\mathrm{GP})$ was prepared and characterized, and the effect of $\mathrm{nHAp}$ on the hydrogel was examined.
\end{abstract}

Methods: Hydrogels (Zn-CS/ $\beta-G P, Z n-C S / n H A p / \beta-G P)$ were prepared using the sol-gel method. Characterization was carried out by scanning electron microscopy (SEM), energy dispersive spectroscopy (EDX), Fourier transform infrared spectroscopy (FTIR), and X-ray diffraction (XRD) as well as swelling, protein adsorption, and exogenous biomineralization studies. Expression of osteoblast marker genes was determined by real-time reverse transcriptase polymerase chain reaction (RT-PCR) and western blot analyses. In vivo bone formation was studied using a rat bone defect model system.

Results: The hydrogels exhibited sol-gel transition at $37^{\circ} \mathrm{C}$. The presence of $\mathrm{nHAp}$ in the $\mathrm{Zn}-\mathrm{CS} / \mathrm{nHAp} / \beta$-GP hydrogel enhanced swelling, protein adsorption, and exogenous biomineralization. The hydrogel was found to be non-toxic to mesenchymal stem cells. The addition of nHAp to the hydrogel also enhanced osteoblast differentiation under osteogenic conditions in vitro and accelerated bone formation in vivo as seen from the depositions of apatite and collagen.

Conclusions: The synthesized injectable hydrogel ( $\mathrm{Zn}-\mathrm{CS} / \mathrm{nHAp} / \beta-\mathrm{GP})$ showed its potential toward bone formation at molecular and cellular levels in vitro and in vivo. The current findings demonstrate the importance of adding nHAp to the hydrogel, thereby accelerating potential clinical application toward bone regeneration.

Keywords: Chitosan, Zinc, nHAp, $\beta$-Glycerophosphate, Runx2, Bone

\section{Background}

The rapid shift in the treatment regime from bone grafting to bone tissue engineering is due to surgical complications and biocompatibility issues in terms of immunogenic responses associated with tissue grafting

\footnotetext{
*Correspondence: selvamn2@yahoo.com

${ }^{1}$ Department of Biotechnology, School of Bioengineering, SRM

University, Kattankulathur 603203, Tamil Nadu, India

Full list of author information is available at the end of the article
}

$[1,2]$. The use of polymeric scaffolds and ceramic particles has shown promising improvements, extending their application as bone graft materials. Hydrogels have mechanical and structural properties that are very similar to those of natural tissues and extracellular matrices (ECMs) [3]. Hydrogels are exemplified as bone grafts in non-load-bearing regions because of their high degree of flexibility, low toxicity, biocompatibility, biodegradability, sensitivity to external stimuli, injectability, and easily 
modifiable properties and because they can be used for timed release of growth factors [4-8].

Chitosan (CS), which is a deacetylated derivative of chitin, is a linear aminopolysaccharide that has been widely used in biomedical applications [9-14]. CS possesses both structural and compositional similarity to glycosaminoglycans (GAGs) and hence elicits minimal immune response [15]. It demonstrates efficient chelating abilities with metal ions [16] and exhibits swelling properties [17]. CS-based hydrogels have the potential to swell and dehydrate depending on the surrounding environment [18]. Zinc $(\mathrm{Zn})$ is an important trace element found in bone and has structural and regulatory cellular functions [19]. It stimulates osteoblastogenesis and suppresses osteoclastogenesis [20, 21]. In addition, $\mathrm{Zn}$ possesses excellent antimicrobial properties [22], which are widely exploited in bone implant materials to tackle implant-associated microbial infections.

Hydroxyapatite (HAp) is a mineral component of natural bone and exhibits osteoconductive properties, osteoinductive properties, bone bonding abilities, and slow degradation in situ [23]. A significant increase in protein adsorption and osteoblast adhesion was observed on nanosized ceramic materials, compared with that on traditional micron-sized ceramic materials [24]. The addition of HAp improves stiffness, interconnectivity, and osteogenic potential in collagen-based scaffolds for bone tissue engineering applications [25]. Organic phosphates, in particular $\beta$-glycerophosphate ( $\beta$-GP), have been used to induce mineralization in cell culture systems [26]. $\beta$-GP serves as a source of inorganic phosphates when hydrolyzed by alkaline phosphatase (ALP), and it has been used as an osteogenic supplement in cultures of human bone marrow stromal cells (hBMSCs) [27, 28]. By adding $\beta$-GP, which is a weak base, to aqueous chitosan solutions, the polymer remains in solution at neutral $\mathrm{pH}$ and room temperature, while homogeneous gelation of this system can be triggered by heat [29]. Controlled hydrogel formation with temperature increase takes place because of the thermally induced transfer of protons from the amine groups of chitosan to the $\left(\mathrm{PO}_{4}\right)^{2-}$ groups of $\beta$-GP [30, 31].

Based on the biomaterial properties mentioned above, in this study, we aimed to synthesize and characterize an injectable thermosensitive hydrogel containing zincdoped chitosan/nanohydroxyapatite/ $\beta$-glycerophosphate (Zn-CS/nHAp/ß-GP). Most importantly, the impact of nHAp on the osteogenic potential of the synthesized hydrogel was determined in vitro and in vivo. The molecular mechanism behind the bone formation potential of the hydrogel was also examined. In vitro bone regeneration promoted by the hydrogel was confirmed in vivo in critical-sized bone defects in rats.

\section{Results and discussion}

\section{Hydrogel preparation}

$\mathrm{Zn}-\mathrm{CS} / \beta-\mathrm{GP}$ and $\mathrm{Zn}-\mathrm{CS} / \mathrm{nHAp} / \beta-\mathrm{GP}$ solutions were prepared by drop-wise addition of an optimized molar concentration of pre-cooled $\beta$-GP to pre-cooled solutions of $\mathrm{Zn}$-CS and $\mathrm{Zn}-\mathrm{CS} / \mathrm{nHAp}$ under continuous mixing. The sol form of the hydrogel formed at $4^{\circ} \mathrm{C}$ was transferred to $37^{\circ} \mathrm{C}$ for gelation. The gelation time was found to be $>10 \mathrm{~min}$ at $\mathrm{pH}$ 7. The acidic $\mathrm{pH}$ of the CS solution changed to 7 with the addition of $\beta$-GP.

\section{Physicochemical characterization of hydrogel}

Scanning electron microscopy (SEM) analysis of the $\mathrm{Zn}-\mathrm{CS} / \beta-\mathrm{GP}$ hydrogel (Figure $1 \mathrm{a}, \mathrm{b}$ ) and the $\mathrm{Zn}$-CS/ $\mathrm{nHAp} / \beta-\mathrm{GP}$ hydrogel (Figure 1c, d) revealed porous architectures indicative of the presence of both microand macro-sized pores. The pores in the hydrogels were uniformly present and highly interconnected. In both $\mathrm{Zn}-\mathrm{CS} / \beta-\mathrm{GP}$ and $\mathrm{Zn-CS/nHAp/ \beta -GP}$ hydrogels, the diameter of the pores was in the range of $100-150 \mu \mathrm{m}$. This was a suitable pore size for cell penetration into the hydrogels and aided in nutrient transport and metabolic waste disposal. The magnified image of the hydrogel with nHAp shown in Figure 1d indicates that the addition of nHAp resulted in the deposition of sharp needle-shaped nanoparticles along the pore walls and struts, which acted as nucleating sites for mineral deposition, protein adsorption, and cell attachment because of their nanoarchitecture [32-34].

$\mathrm{X}$-ray diffraction (XRD) analyses of the individual components employed in the preparation of the hydrogels and the final resulting hydrogels are shown in Figure 1e. The appearance of broad peaks between $20^{\circ}$ and $30^{\circ}$ indicated the semi-crystalline nature of chitosan. The sharper peaks observed at $31.66^{\circ}, 34.2^{\circ}, 36.16^{\circ}, 47.86^{\circ}, 56.52^{\circ}$, $62.66^{\circ}$, and $67.80^{\circ}$ corresponded to the (100), (002), (101), (102), (110), (103), and (112) lattice planes, respectively, of the wurtzite phase of $\mathrm{ZnO}$. The values are in strong agreement with those of standard $\mathrm{ZnO}$ in JCPDS card No 36-1451 [35]. The occurrence of phases corresponding to $\mathrm{CS}, \mathrm{ZnO}, \mathrm{nHAp}$, and $\beta$-GP was clearly evident in the final hydrogel because of its crystalline nature.

The Fourier transform infrared spectroscopy (FTIR) spectra of the individual components and of the hydrogels are shown in Figure $1 \mathrm{f}$ and g. The absorption band at $1,600 \mathrm{~cm}^{-1}$, representing the "free amine" group of chitosan, disappeared in the $\mathrm{Zn}$-CS complex and was replaced by a new peak at $1,657 \mathrm{~cm}^{-1}$, corresponding to the Zn-CS complex [36]. Chitosan showed an absorption peak at $3,425 \mathrm{~cm}^{-1}$, which was attributed to the combined peaks of the $-\mathrm{NH}_{2}$ and $-\mathrm{OH}$ stretching vibration. This broader and stronger peak of chitosan was shifted to a higher wavenumber at $3,430 \mathrm{~cm}^{-1}$ in $\mathrm{Zn}-\mathrm{CS}$, 

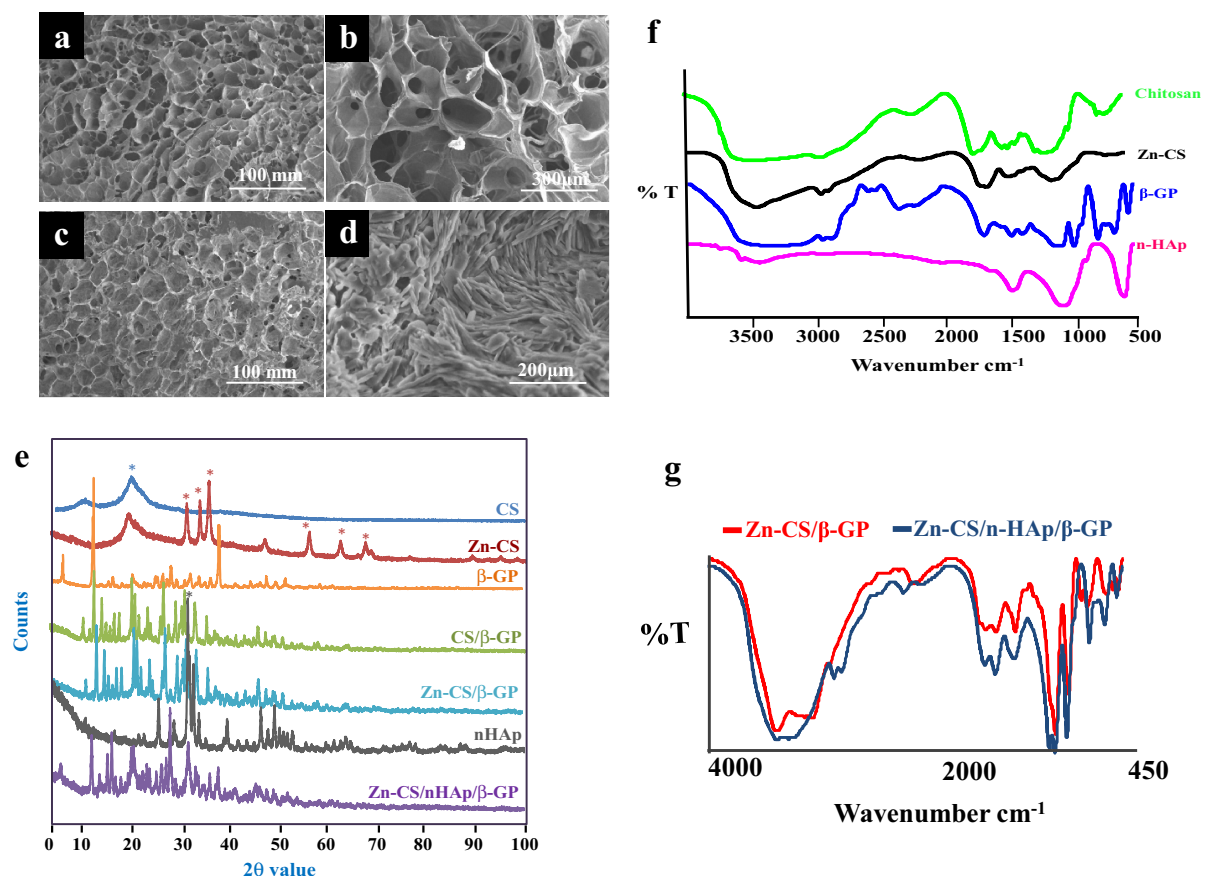

g

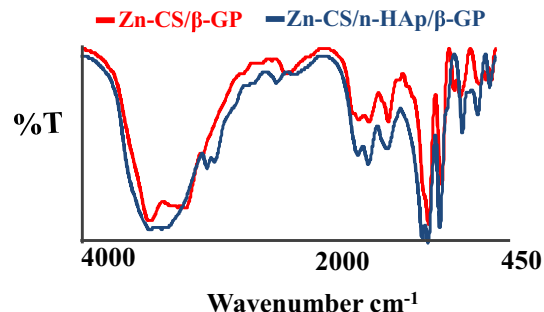

Figure 1 Physicochemical characterization of the hydrogels. Scanning electron microscopic images of $\mathbf{a} Z \mathrm{Zn}-\mathrm{CS} / \beta-\mathrm{GP}$ and $\mathbf{c} \mathrm{Zn}-\mathrm{CS} / \mathrm{nHAp} / \beta$-GP; $\mathbf{b}$ and $\mathbf{d}$ are magnified images of the above, respectively. Pores greater than $150 \mu \mathrm{m}$ in diameter were seen in both hydrogels. The presence of nHAp along the matrix of chitosan is clearly visible under high magnification. $\mathrm{e}$ XRD spectra of the individual components and of the hydrogels. FTIR spectra of $\mathbf{f}$ the individual components and of $\mathbf{g}$ the $Z n-C S / \beta-G P$ and $Z n-C S / n H A p / \beta-G P$ hydrogels.

indicating a strong interaction between these groups and $\mathrm{ZnO}$. The absorption peak at $2,921 \mathrm{~cm}^{-1}$ was attributed to the asymmetric stretching of $-\mathrm{CH}_{3}$ in chitosan, and the absorption peaks at 1,657 and $1,093 \mathrm{~cm}^{-1}$ were ascribed to the bending vibration of the $-\mathrm{NH}_{2}$ group and the $\mathrm{C}-\mathrm{O}$ stretching group, respectively. All of these interactions clearly described the attachment of zinc oxide to chitosan chains. Standard FTIR spectra of nHAp and $\beta$-GP were also recorded to study the interactions among the gelforming components. The spectrum of $\beta$-GP showed the bending and stretching vibration modes of $\mathrm{PO}_{4}$, which were identified by the peaks at 548 and $653 \mathrm{~cm}^{-1}$, respectively. The individual spectrum of nHAp showed the $\Upsilon_{1}$ and $\Upsilon_{4}$ absorption bands of $\mathrm{PO}_{4}$ at 1,050 and $577 \mathrm{~cm}^{-1}$, respectively [37]. In addition, the peak at $3,567 \mathrm{~cm}^{-1}$ in the nHAp spectrum corresponded to the $-\mathrm{OH}$ stretching mode of stoichiometric HAp [38].

The FTIR spectrum of the $\mathrm{Zn}-\mathrm{CS} / \beta-\mathrm{GP}$ hydrogel was compared with that of the $\mathrm{Zn}$-CS/nHAp/ $/$-GP hydrogel (Figure $1 \mathrm{~g}$ ) to identify important interactions between $\mathrm{Zn}-\mathrm{CS} / \beta-\mathrm{GP}$ and the bioactive component nHAp. The $\mathrm{Zn}-\mathrm{CS} / \mathrm{nHAp} / \beta-\mathrm{GP}$ hydrogel revealed peaks at 1,410 and $1,573 \mathrm{~cm}^{-1}$ attributing to $\mathrm{C}=\mathrm{O}$ stretching, strong peaks at 2,848 and $2,936 \mathrm{~cm}^{-1}$ belonging to the $\mathrm{C}-\mathrm{H}$ stretching region, and small peaks between 2,160 and $2,255 \mathrm{~cm}^{-1}$ corresponding to $\mathrm{C}=\mathrm{C}$. The peaks at 1,074 and $2,848 \mathrm{~cm}^{-1}$ indicated amide II bands, and the peaks at $1,664,1,573$, and $1,550 \mathrm{~cm}^{-1}$ were assigned to amide I $(\mathrm{C}=\mathrm{O})$, amino $\left(-\mathrm{NH}_{2}\right)$, and amide II $(-\mathrm{NH})$, respectively [39]. The peak at $960 \mathrm{~cm}^{-1}$ in the $\mathrm{Zn}-\mathrm{CS} / \beta-\mathrm{GP}$ hydrogel, representing the $\Upsilon_{1}$ absorption band of $\mathrm{PO}_{4}$, was intensified and shifted to a higher wavenumber of $971 \mathrm{~cm}^{-1}$ with the addition of nHAp. This result indicated a strong interaction between nHAp and $\mathrm{Zn}-\mathrm{CS}$ in the hydrogel.

\section{Hydrogel characteristics with the addition of nHAp}

Swelling behavior and structural integrity are two critical design variables in constructing hydrogels and other scaffolding materials. CS has the ability to readily swell up when exposed in a biological environment. Figure 2a indicates increased fluid uptake associated with the addition of nHAp particles to the hydrogel. A drop in the swelling behavior was noticed with an increase in the incubation period to greater than $12 \mathrm{~h}$. The higher rate of swelling associated with hydrogels containing nHAp may be due to the hydrophilicity offered by the free -OH groups of nHAp. Fluid retention results in the relaxation of mechanically coiled chains of chitosan, leading to an increase in surface area. In turn, the increase in internal surface area caused by swelling facilitates the infiltration of cells into the scaffolds. Moreover, increased swelling enables efficient transport of nutrients from the culture media and ensures better 

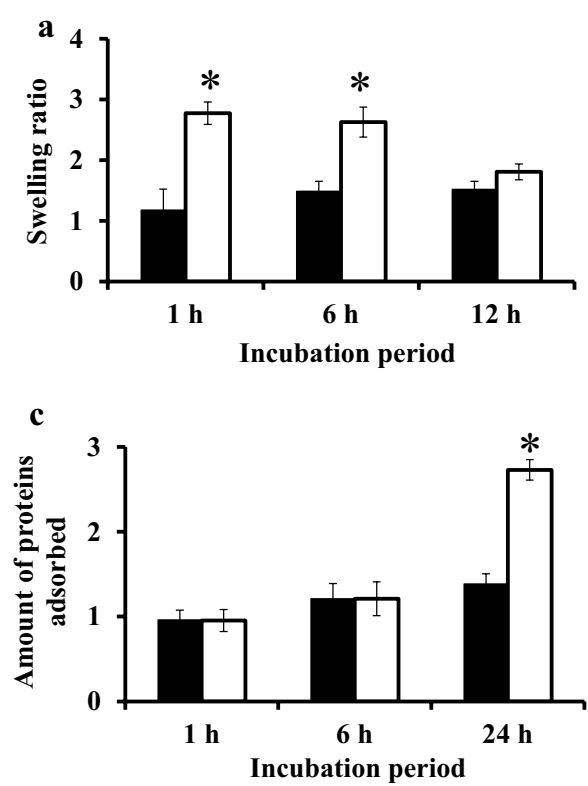

\section{- Zn-CS/ $/$-GP \\ $\square \quad$ Zn-CS/nHAP/ß-GP}

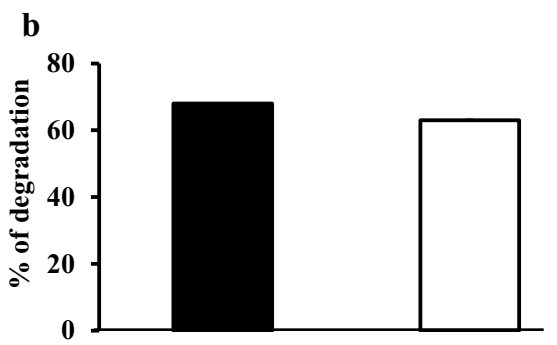

Figure 2 a Swelling studies of $Z n-C S / \beta-G P$ and $Z n-C S / n H A p / \beta-G P$ hydrogels. Addition of nHAp significantly increased the water retention capacity of the hydrogel. $\mathbf{b}$ Degradation studies of $\mathrm{Zn}-\mathrm{CS} / \beta-\mathrm{GP}$ and $\mathrm{Zn}-\mathrm{CS} / \mathrm{nHAp} / \beta-\mathrm{GP}$ hydrogels. Addition of $\mathrm{nHAP}$ had no effect on the degradation characteristics of the hydrogel. Asterisk indicates significant changes compared with $\mathrm{Zn}-\mathrm{CS} / \beta-\mathrm{GP}(p<0.05)(\mathrm{n}=6)$. c Protein adsorption studies on $\mathrm{Zn}-\mathrm{CS} / \beta-\mathrm{GP}$ and $\mathrm{Zn}-\mathrm{CS} / \mathrm{nHAp} / \beta$-GP hydrogels.

probability of cell infusion in a 3D pattern, mimicking cell growth under physiological conditions in vivo [40, 41]. The persistence and rate of degradation of any implanted material in vivo are the key factors that affect the rate of bone formation. Glycosidic bonds in the CS polymeric network are a major target for hydrolytic scission by lysozymes. The chains of $\mathrm{N}$-acetylglucosamine in CS are linked by glycosidic bonds, and their degradation will lead to the release of amino sugars, which can be utilized for several metabolic pathways [42]. In addition, the degradation of scaffolds is essential for the release of bioactive ingredients and determines the mechanical strength of any biomaterial. The degradation rate of both hydrogels remained the same at $48 \mathrm{~h}$. From Figure 2b, it is clear that the addition of nHAp had no effect on the degradation of the hydrogel.

Protein adsorption is a pre-requisite for cell-biomaterial interaction, which can be strengthened by the presence of nanoparticles in the composites. The protein adsorption ability of the hydrogels was studied at different times (Figure 2c). Initial protein adsorption is a vital property of a successful tissue-engineered implant. The addition of nHAp significantly increased the amount of protein adsorbed onto the hydrogel at $24 \mathrm{~h}$. This effect could have been due to the increased hydrophilicity of the hydrogel, which mediated enhanced protein adsorption. In addition, the nanostructures of hydroxyapatite in the hydrogel offered increased surface area for the adsorption of proteins [43].
The in vitro exogenous biomineralization of the hydrogels prepared was examined by immersing them in simulated body fluid (SBF) solutions for 21 days. The presence of apatite crystals on the surface of the hydrogels was examined and confirmed by SEM analyses (Figure 3a-d). Figure $3 a$ and $b$ represent the SEM images of exogenous biomineralized $\mathrm{Zn}-\mathrm{CS} / \beta-\mathrm{GP}$ and $\mathrm{Zn}-\mathrm{CS} / \mathrm{nHAp} / \mathrm{\beta}-\mathrm{GP}$ hydrogels, respectively. Figure $3 c$ and $d$ represent the magnified images of the above. The pattern of apatite formation was intense on the surface of the hydrogels containing nHAp (Figure 3d). This could be due to the availability of negatively charged hydroxyl groups on hydroxyapatite that acted as nucleation sites to initiate crystal deposition. Furthermore, the presence of calcium and phosphate ions in the biomineralized $\mathrm{Zn}-\mathrm{CS} / \beta-\mathrm{GP}$ (Figure 3e) and $\mathrm{Zn}$-CS/nHAp/ $\beta$-GP (Figure 3f) hydrogels was confirmed in the energy dispersive spectroscopy (EDX) spectra. The characteristic diffraction peaks of hydroxyapatite at values of $2 \theta$ from $31.8^{\circ}$ to $52.5^{\circ}$, in accordance to JCPDS-09-0432, were observed in all tested samples (Figure 3g). The observed sharper peaks implied that the degree of crystallinity of the hydrogel samples had increased after biomineralization.

The antimicrobial nature of any implanted graft material aids in the persistence of the implant by preventing microbial attacks associated with surgeries. The hydrogels exhibited a bactericidal effect against Gram-negative and Gram-positive bacteria, such as Escherichia coli and 


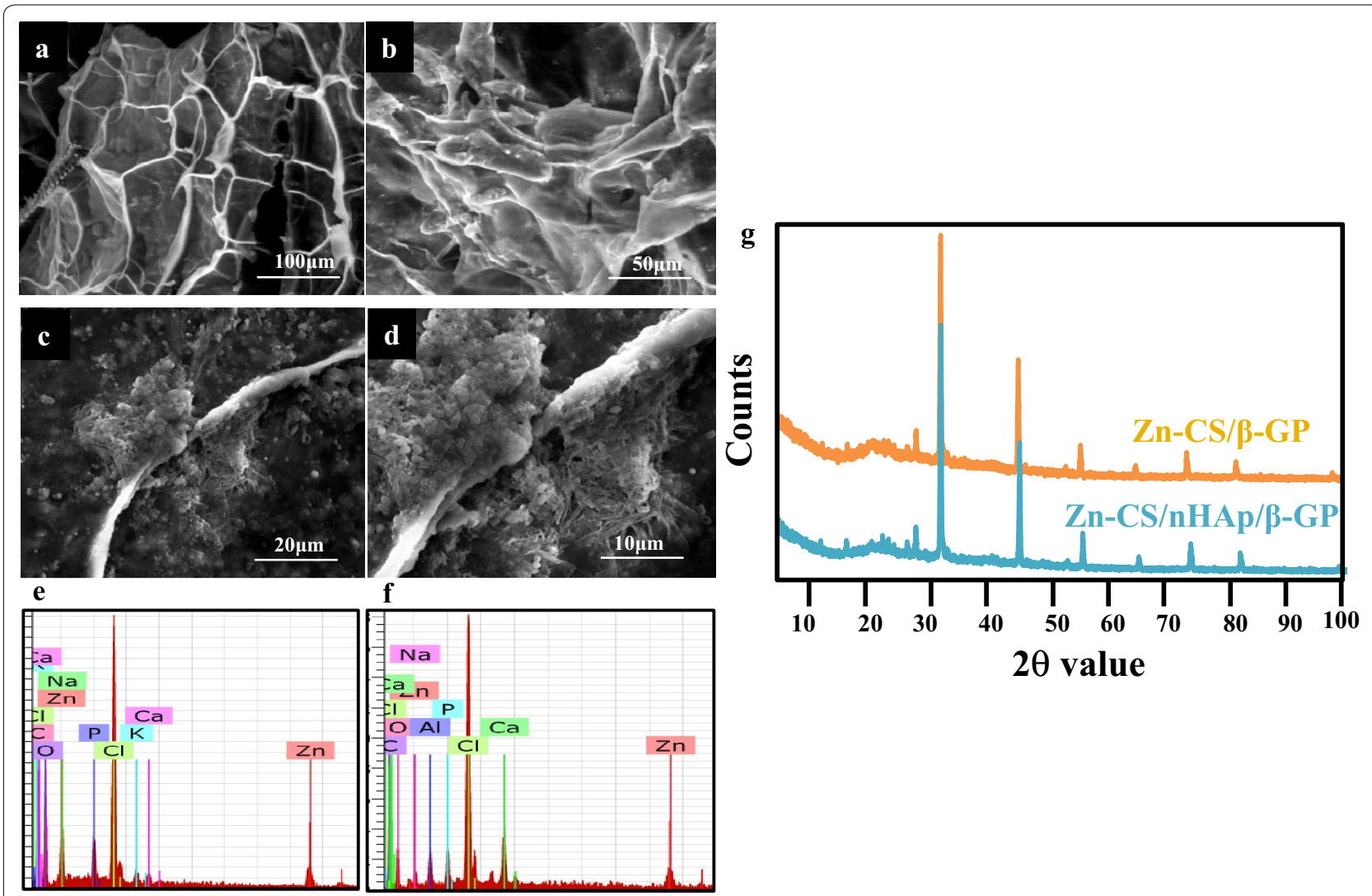

Figure 3 SEM images of exogenous biomineralized $\mathbf{a} \mathrm{Zn}-\mathrm{CS} / \beta-\mathrm{GP}$ and $\mathbf{b} \mathrm{Zn}-\mathrm{CS} / \mathrm{nHAp} / \boldsymbol{\beta}$-GP hydrogels in SBF for 21 days. $\mathbf{c}$ and $\mathbf{d}$ are $m a g n i f i e d$ images of the above, respectively. EDX spectra of $\mathbf{e} \mathrm{Zn}-\mathrm{CS} / \beta-\mathrm{GP}$ and $\mathbf{f} \mathrm{Zn}-\mathrm{CS} / \mathrm{nHAp} / \beta$-GP hydrogels. $\mathbf{g}$ XRD spectra of the mineralized hydrogels.

Table 1 Zone of inhibition observed against Gram-negative and Gram-positive organisms

\begin{tabular}{|c|c|c|}
\hline \multirow[t]{2}{*}{ Hydrogel } & \multicolumn{2}{|c|}{ Zone of inhibition (mm) } \\
\hline & Escherichia coli & Streptococcus pyogenes \\
\hline $\mathrm{Zn}-\mathrm{CS} / \beta-\mathrm{GP}$ & $8.0 \pm 0.013$ & $9.3 \pm 0.305$ \\
\hline $\mathrm{Zn}-\mathrm{CS} / \mathrm{n}-\mathrm{HAp} / \beta-\mathrm{GP}$ & $8.0 \pm 0.057$ & $9.6 \pm 0.252$ \\
\hline
\end{tabular}

Addition of nHAp induced no significant change in the antimicrobial behavior of the hydrogel.

Streptococcus pyogenes, respectively. The antimicrobial activity of the $\mathrm{Zn}-\mathrm{CS} / \mathrm{nHAp} / \beta-\mathrm{GP}$ hydrogel was not significantly different compared with that of the $\mathrm{Zn}-\mathrm{CS} /$ $\beta$-GP hydrogel (Table 1). Overall, these results (Figures 2, 3) clearly indicated the superiority of the nHAp-incorporated hydrogel over the native hydrogel (without nHAp).

\section{Biocompatible nature of the synthesized hydrogel}

Biomaterials intended for tissue engineering applications should not exert any toxicity on mammalian cells. The dissolution of ions from biomaterials plays a vital role in regulating cytotoxicity. Impedance of cell growth and alterations in membrane permeability are signs of cytotoxicity. Hence, the synthesized $\mathrm{Zn}-\mathrm{CS} / \mathrm{nHAp} / \beta-\mathrm{GP}$ hydrogel was subjected to an indirect 3-(4,5-dimethythiazol-2-yl)-2,5-diphenyltetrazolium bromide (MTT) assay. Mouse mesenchymal stem cells (mMSCs) were incubated with medium that was conditioned by immersing hydrogels therein for $24 \mathrm{~h}$. Cells incubated in normal media served as negative controls, and cells treated with $0.1 \%$ Triton X-100 served as positive controls. From Figure $4 \mathrm{a}$, it is obvious that the cells experienced cytotoxicity when cultured in $100 \mu \mathrm{L}$ of conditioned medium, which was the amount equivalent to $5 \mathrm{mg}$ of hydrogel. Since there was no discernible toxicity associated with $50 \mu \mathrm{L}(2.5 \mathrm{mg})$ of conditioned medium, this condition was chosen for further studies. Direct measurement of cell viability was also performed with fluorescein diacetate (FDA) staining of control mMSCs (Figure 4bI, II) and of the mMSCs in the $\mathrm{Zn}$-CS/nHAp/ $\beta$-GP hydrogel (Figure $4 \mathrm{bIII}, \mathrm{IV})$. The results showed the non-toxic nature of the hydrogel, as indicated by the distinct cellular morphology and highly spread cellular extensions. 


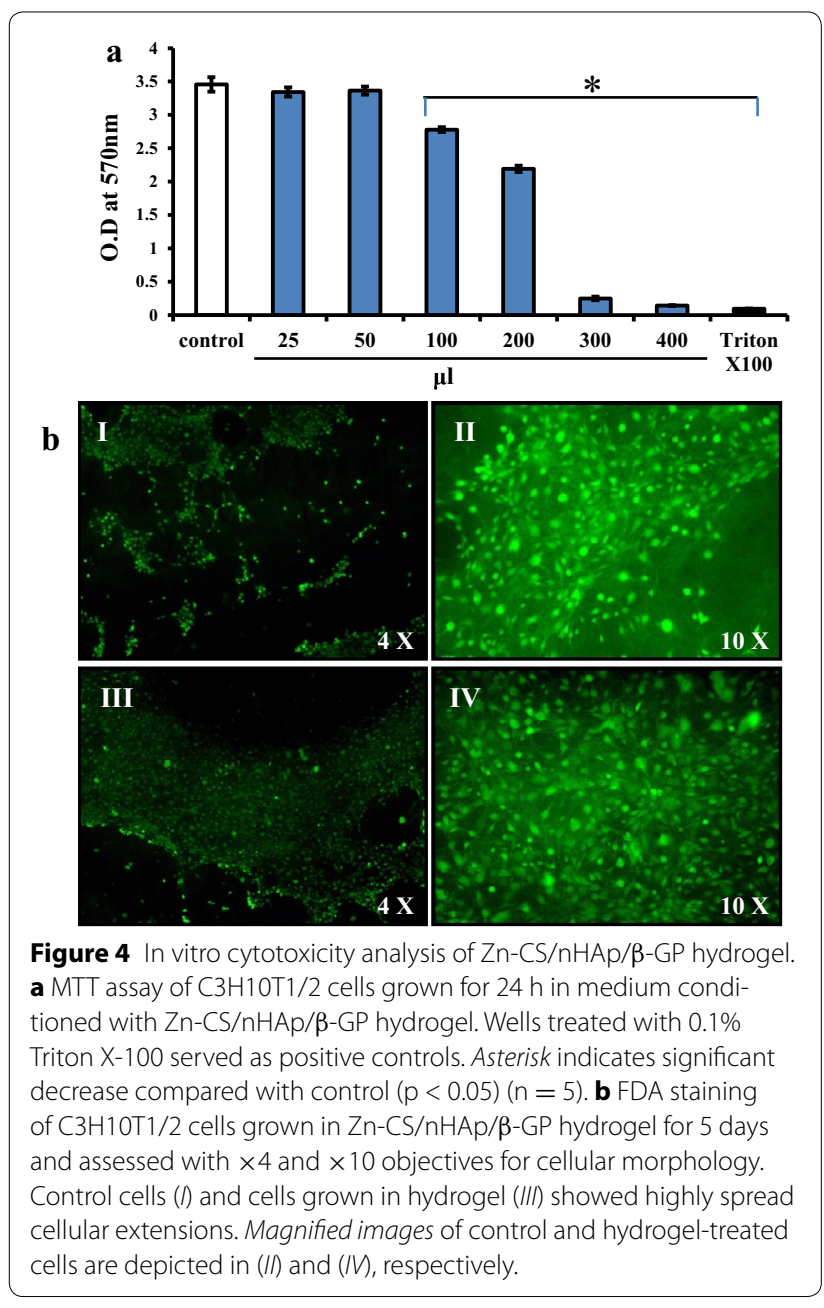

mMSC differentiation to osteoblasts at the cellular level To determine the capability of hydrogels and the significance of nHAp in promoting MSC differentiation into osteoblasts, mMSCs were grown in the conditioned media obtained from the $\mathrm{Zn}-\mathrm{CS} / \beta-\mathrm{GP}$ hydrogel or from the $\mathrm{Zn}$-CS/nHAp/ $\beta$-GP hydrogel, either in the presence or absence of osteogenic stimulants for 7 and 14 days (Figure 5). Calcium deposition was assessed by alizarin red staining. Microscopic images of the biomineralized deposits indicated that, in the presence of osteogenic stimulation, the addition of nHAp in the $\mathrm{Zn}-\mathrm{CS} / \beta-\mathrm{GP}$ hydrogel promoted better osteoblast differentiation at 7 days (Figure 5c) and 14 days (Figure $5 \mathrm{~d}$ ) compared with the $\mathrm{Zn}-\mathrm{CS} / \beta-\mathrm{GP}$ hydrogel (Figure $5 \mathrm{a}, \mathrm{b}$ ). Quantification data for the alizarin red staining also indicated increased mineralization in the $\mathrm{Zn}-\mathrm{CS} / \mathrm{nHAp} / \beta$-GP hydrogel at 7 days (Figure 5e) and 14 days (Figure $5 f$ ). Hence, the hydrogel exerted maximal differentiation potential under osteogenic conditions and in the presence of nHAp, indicating its osteoconductive nature.

\section{mMSC differentiation into osteoblasts at the molecular} level

Real-time reverse transcriptase polymerase chain reaction (RT-PCR) was carried out to determine the expression of osteoblastic differentiation marker genes such as alkaline phosphatase (ALP), type-I collagen (COL-I), osteocalcin (OC), and bone transcription factor Runx2 at the molecular level in mMSCs incubated with the hydrogels (Figure 6). Increased mRNA levels of ALP, COL-I, and Runx2 were observed in cells incubated with the hydrogel containing nHAp (Zn-CS/nHAp/ $\beta-\mathrm{GP})$ for 7 days in osteogenic medium compared with those observed in the Zn-CS/ $\beta$-GP hydrogel (Figure 6a). A significant increase in the mRNA level of OC was found in mMSCs after 14 days of incubation with the $\mathrm{Zn}-\mathrm{CS} / \mathrm{nHAp} / \beta-\mathrm{GP}$ hydrogel in the presence of osteogenic medium (Figure $6 \mathrm{~b}$ ). Although the mRNA expression of Runx 2 was stimulated by $n$ HAp in the $\mathrm{Zn}-\mathrm{CS} / \mathrm{nHAp} / \beta$-GP hydrogel even in normal medium, maximal Runx2 expression was observed in osteogenic medium. Runx2 is an essential transcription factor for the expression of various osteoblast-specific marker genes, namely, ALP, COL-I, and OC [44]. ALP and COL-1 are early differentiation marker genes, whereas $\mathrm{OC}$ is a late marker gene of osteoblast differentiation. ALP plays a role in the conversion of inorganic pyrophosphate into inorganic phosphate, a process that enhances mineralization process [45]. COL-I aids in the deposition of collagen, the most abundant ECM protein in bone. The voids in the collagen molecules act as the sites of deposition for hydroxyapatite crystals, facilitating subsequent bone mineralization [46]. OC is a major non-collagenous protein component of the bone ECM, acting as a regulator of bone crystal growth by mediating its high affinity binding to hydroxyapatite crystals [47].

The expression of the Runx2 protein was also determined. At 7 and 14 days of cell incubation with $\mathrm{Zn}-\mathrm{CS} /$ $\beta$-GP and $\mathrm{Zn}-\mathrm{CS} / \mathrm{nHAp} / \beta-\mathrm{GP}$ hydrogels in osteogenic medium, the expression of Runx2 was higher than that in normal medium (Figure $7 \mathrm{a}, \mathrm{c}$ ). The addition of $\mathrm{nHAp}$ in the $\mathrm{Zn}-\mathrm{CS} / \beta-\mathrm{GP}$ hydrogel stimulated higher Runx2 protein expression than that seen in the $\mathrm{Zn}-\mathrm{CS} / \beta-\mathrm{GP}$ hydrogel at an incubation period of 7 days (Figure $7 \mathrm{a}$ ). The densitometry scanning of western blotting is shown in Figure $7 \mathrm{~b}$ and $\mathrm{d}$. The consolidation of gene and protein expression results (Figures 6,7) suggested that the presence of nHAp in the hydrogel enhanced the expression of Runx2 and osteoblast differentiation marker genes under osteogenic conditions, depicting the osteoconductive nature of the hydrogel.

\section{Healing of critical-sized bone defects in rat tibia in vivo}

We next assessed the bone-healing property of the hydrogels in rats with tibial defects as well as the significance 


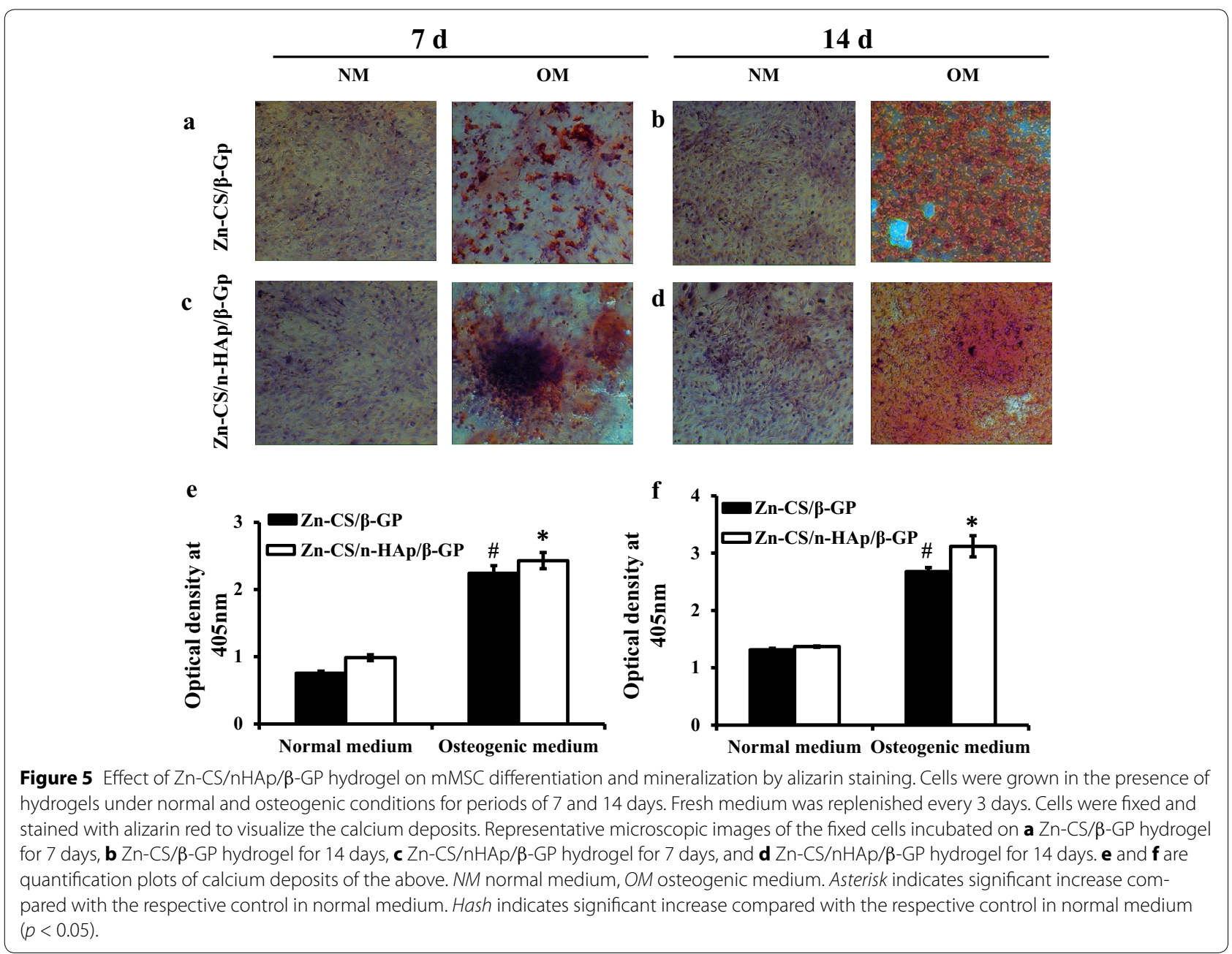

of nHAp in the hydrogels. From radiographic images taken 2 weeks post-surgery, better tissue organization was observed in tibiae treated with $\mathrm{Zn}-\mathrm{CS} / \mathrm{nHAp} / \beta-\mathrm{Gp}$ hydrogels than in tibiae treated with $\mathrm{Zn}-\mathrm{CS} / \beta-\mathrm{GP}$ hydrogels and in control tibiae (Figure 8a). The radiographs showed that, in the control group, the tibial bone defect was devoid of any implanted hydrogel, resulting in a radiolucent gap with no signs of the drill hole being filled. The presence of nHAp in the $\mathrm{Zn}-\mathrm{CS} / \mathrm{nHAp} / \beta$-Gp hydrogel resulted in better wound closure and bone formation, in contrast with the findings for hydrogel without nHAp and the control. The radiographs depicted minimal periosteal reaction and smoothening of cortical bone defect edges in the control and $\mathrm{Zn}-\mathrm{CS} / \beta$-GP-treated groups. The shape of the bone defect changed to an oval morphology, suggesting the initiation of bone healing. Histological analysis involving hematoxylin and eosin (H\&E) staining (Figure 8b) and collagen staining (Figure 8c) was performed. Initiation of bone formation was found to be more prominent (purple color) in $\mathrm{Zn}-\mathrm{CS} / \mathrm{nHAp} / \beta-\mathrm{GP}$ hydrogel-treated animals, whereas few areas with purple color were observed in $\mathrm{Zn}-\mathrm{CS} / \beta$-Gp hydrogel-treated animals. No apparent bone formation was observed in control animals (Figure 8b). The presence of nHAp in the hydrogel was a key factor in bone crystal deposition and acted as a nucleating site for bone formation. Collagen is the main component of the ECM involved in the bone repair mechanism. It is clear that collagen deposition (blue-colored deposits) was much more intense in $\mathrm{Zn}-\mathrm{CS} / \mathrm{nHAp} / \beta-\mathrm{GP}$ hydrogel-treated animals than in the control or $\mathrm{Zn}-\mathrm{CS} / \beta$-GP hydrogel-treated animals (Figure $8 \mathrm{c}$ ). Thus, the addition of nHAp in the $\mathrm{Zn}-\mathrm{CS} / \beta-\mathrm{GP}$ hydrogel improved bone formation and closure of rat tibial bone defects in vivo.

\section{Conclusions}

The current investigations implicate the importance of incorporating nHAp in a thermosensitive CS-based hydrogel to improve its physical and biological characteristics. Increased protein adsorption, controlled swelling, 


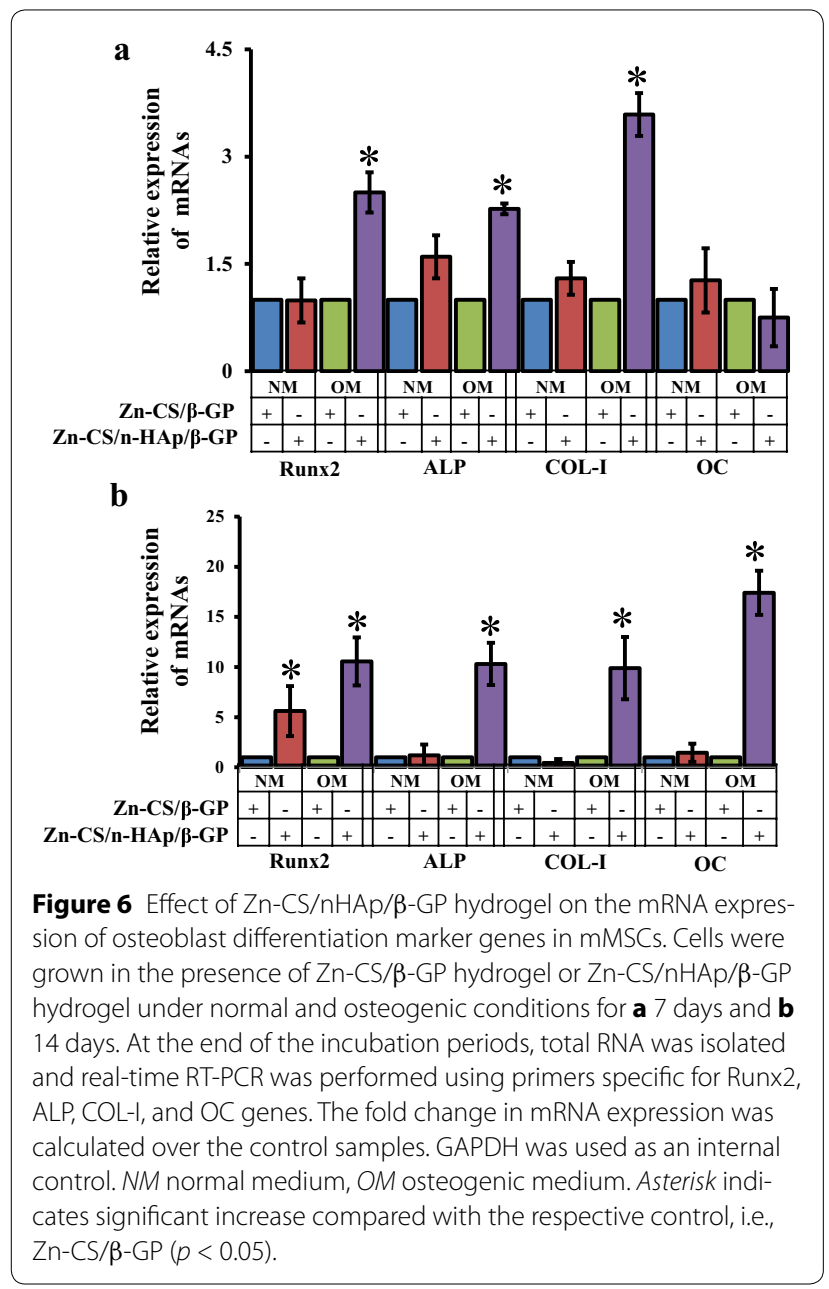

and decreased susceptibility to lysozyme degradation were exhibited with the addition of nHAp. The hydrogel was also found to be osteoconductive in nature, promoting the differentiation of mMSCs into osteoblasts through the upregulation of Runx2 expression. Moreover, the use of $\mathrm{Zn}-\mathrm{CS} / \mathrm{nHAp} / \beta$-GP hydrogels promoted bone healing in critical-sized rat tibial defects. The current findings demonstrate the advantages of adding nHAp to hydrogels, implying their potential clinical application in bone regeneration.

\section{Methods}

\section{Preparation of Zn-doped CS}

Zn-doped CS was prepared under refluxing conditions by using an acidic solution of chitosan and a precursor solution for zinc. The procedure has been previously described in detail [48].

\section{Preparation of $\mathrm{Zn}-\mathrm{CS} / \mathrm{nHAp} / \mathrm{\beta}-\mathrm{GP}$}

$\mathrm{Zn}$-doped (2\% w/v) CS was weighed and dissolved in $0.1 \mathrm{M}$ acetic acid to obtain a clear solution. $\beta$-glycerophosphate
( $\beta$-GP) disodium salt hydrate (Sigma Aldrich) solutions of appropriate molar concentration were prepared by dissolving calculated amounts of $\beta$-GP in distilled water. Both solutions were pre-cooled to $4^{\circ} \mathrm{C}$ before hydrogel preparation. nHAp (Sigma Aldrich) was sonicated in distilled water at $0.1 \%(\mathrm{w} / \mathrm{v})$ to obtain a homogeneous dispersion and pre-cooled to $4^{\circ} \mathrm{C}$ prior to hydrogel formation. To the solution containing $\mathrm{Zn}-\mathrm{CS} / \mathrm{nHAp}, \beta$-GP solution was added drop-wise under continuous mixing. The precooled solutions were mixed together at a ratio of 8:1:1 (Zn-CS: $\beta$-GP:nHAp) with the final concentration of $\beta$-GP in the sol being $0.35 \mathrm{M}$. The sol form of the hydrogel was poured into 24 -well culture plates and incubated at $37^{\circ} \mathrm{C}$ to allow gelation to take place. Gelation was observed within $10 \mathrm{~min}$ at $\mathrm{pH}$ 7. The hydrogel was then stored at $-20^{\circ} \mathrm{C}$ overnight, followed by lyophilization at $-40^{\circ} \mathrm{C}$ for $16 \mathrm{~h}$.

\section{Characterization of the hydrogels}

The external surface morphology and porous structure of the synthesized $\mathrm{Zn}$-doped CS and the freeze-dried $\mathrm{Zn}-\mathrm{CS} / \mathrm{nHAp} / \beta$-GP hydrogel were analyzed by SEM. Thin sections of scaffolds were sliced using a scalpel and the samples were fixed on adhesive carbon tapes, goldcoated, and subjected to SEM analysis using the HR SEM Quanta 200FEG Instrument (Netherlands). The freezedried hydrogel samples were ground into a powder form in liquid nitrogen. The powdered scaffolds were analyzed by XRD with a $2 \theta$ angle of $5^{\circ}-80^{\circ}$ at a speed of $2^{\circ} \mathrm{min}^{-1}$ using an analytical XPERT PRO powder diffractometer operating at a voltage of $40 \mathrm{kV}(\mathrm{Cu} \mathrm{K} \alpha$ radiation). The intermolecular chemical interactions between the various functional groups within the components present in the $\mathrm{Zn}-\mathrm{CS} / \beta-\mathrm{GP}$ hydrogel and the $\mathrm{Zn}-\mathrm{CS} / \mathrm{nHAp} / \beta-\mathrm{GP}$ hydrogel were analyzed by FTIR (American Perkin Elmer Spectrum). The samples were scanned in the range from 4,000 to $450 \mathrm{~cm}^{-1}$.

\section{Swelling studies}

Equal amounts of freeze-dried $\mathrm{Zn}-\mathrm{CS} / \beta-\mathrm{GP}$ and $\mathrm{Zn}-\mathrm{CS} /$ $n H A p / \beta-G P$ hydrogels were measured and their dry weights were noted as $\mathrm{W}_{\mathrm{i}}$. They were then immersed in $1 \times$ PBS for different time periods $(1,6,12$, and $24 \mathrm{~h})$ at $37^{\circ} \mathrm{C}$. At the end of each incubation period, the hydrogels were washed with deionized water to remove any ions adsorbed onto the surfaces and blot-dried using filter paper. The wet weights were recorded as $\mathrm{W}_{\mathrm{f}}$. The swelling ratio of the hydrogel was calculated using the following formula:

$$
\text { Swelling ratio }=\left(\mathrm{W}_{\mathrm{i}}-\mathrm{W}_{\mathrm{t}}\right) /\left(\mathrm{W}_{\mathrm{i}}\right)
$$

\section{Biodegradation studies}

Equal amounts of hydrogel samples were weighed and their initial weights were noted as $\mathrm{W}_{\mathrm{o}}$. They were then 

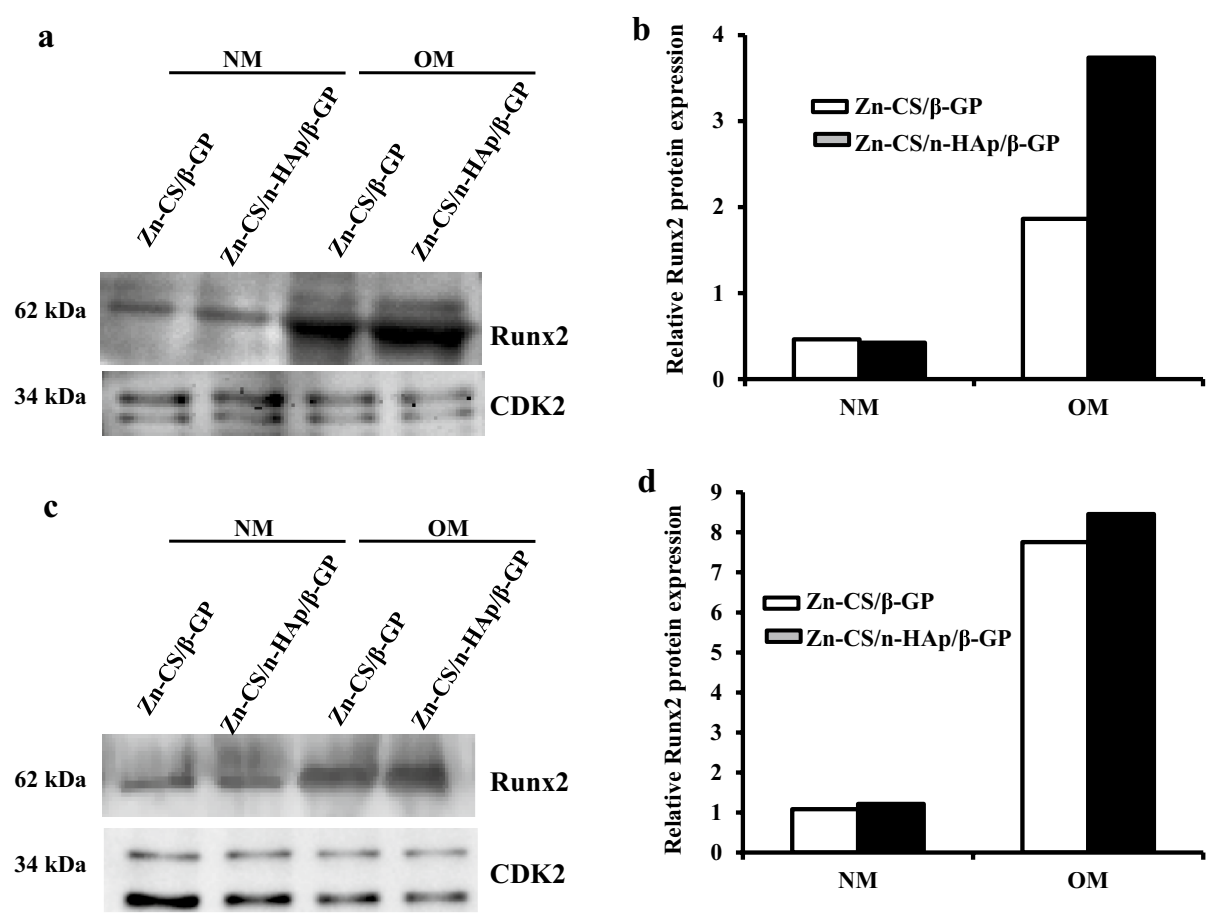

Figure $7 \mathrm{Effect}$ of $\mathrm{Zn}-\mathrm{CS} / \mathrm{nHAp} / \beta$-GP hydrogel on the expression of Runx2 protein. mMSCs were grown in the presence of $\mathrm{Zn}$-CS/ $\beta$-GP hydrogel or $\mathrm{Zn}-\mathrm{CS} / \mathrm{nHAp} / \beta-\mathrm{GP}$ hydrogel under normal and osteogenic conditions for $\mathbf{a} 7$ days and $\mathbf{c} 14$ days. At the end of the incubation periods, whole cells lysates were prepared and separated onto 12\% SDS-PAGE. The proteins were electrophoretically transferred to PVDF membranes and subjected to western blot analysis using Runx2 antibodies. Cdk2 antibodies were used as an internal loading control. $\mathbf{b}$ and $\mathbf{d}$ represent the quantification of Runx2 protein blots as mentioned above using Image Lab software version 4.1 (Bio-Rad). NM normal medium, OM osteogenic medium.

immersed in medium containing lysozymes (Sigma Aldrich) at a concentration similar to that in circulating levels of blood (10,000 U/L) and incubated for $48 \mathrm{~h}$ at $37^{\circ} \mathrm{C}[49]$. At the end of the incubation period, the supernatant was removed and the hydrogels were freeze-dried. The final weight of the freeze-dried hydrogels was noted as $\mathrm{W}_{\mathrm{t}}$. The degradation percentage of the hydrogels was calculated using the following formula:

$$
\text { Biodegradation } \%=\left(\mathrm{W}_{\mathrm{o}}-\mathrm{W}_{\mathrm{t}}\right) / \mathrm{W}_{\mathrm{t}} \times 100
$$

\section{Protein adsorption studies}

Equal amounts of hydrogels were weighed and were subjected to pre-wetting in $100 \%$ ethanol for $1 \mathrm{~h}$, followed by incubation in PBS for $30 \mathrm{~min}$ to reach equilibrium hydration. They were then incubated from 1 to $24 \mathrm{~h}$ in bovine serum albumin solutions (BSA, $5 \mathrm{mg} / \mathrm{mL}$ ) (Sigma Aldrich) at $37^{\circ} \mathrm{C}$. After incubation, the hydrogels were removed and the supernatant solution was used for quantification of unabsorbed proteins by Bradford's assay.

\section{Exogenous biomineralization}

Equal amount of hydrogels were weighed and tested for their biomineralization abilities by immersing them in simulated body fluid (SBF) for a period of 7,14 , and 21 days at $37^{\circ} \mathrm{C}$. Equal volumes of fresh SBF were replaced once every 2 days. The SBF solution was prepared according to a previous report [50]. After the desired time intervals, the scaffolds were removed, washed thrice with deionized water, and lyophilized. The freeze-dried samples were then subjected to FTIR and XRD analyses.

\section{Antimicrobial activity}

Antibacterial activity was determined by the zone of inhibition test using S. pyogenes (Gram-positive bacteria) and E. coli (Gram-negative bacteria). Overnight cultures were prepared. A $100-\mu \mathrm{L}$ aliquot of the overnight culture of the bacteria $\left(1 \times 10^{8} \mathrm{CFU} / \mathrm{mL}\right)$ was spread onto LuriaBertani agar plates, and $20 \mathrm{mg}$ of the lyophilized hydrogel was placed on the plates, followed by incubation for $24 \mathrm{~h}$ at $37^{\circ} \mathrm{C}$. The clear area (zone of inhibition) was measured and the results were tabulated.

\section{Cytotoxicity assessment}

Indirect MTT assay was carried out to test the cytotoxicity of the hydrogels. mMSCs $\left(4 \times 10^{4}\right.$ per $\left.\mathrm{cm}^{2}\right)$ were seeded in 24-well plates. The freeze-dried Zn-CS/ $\mathrm{nHAp} / \beta$-GP hydrogel $(800 \mathrm{mg}$ ) was weighed and soaked in $16 \mathrm{~mL}$ of DMEM for $24 \mathrm{~h}$. The supernatant, termed as 

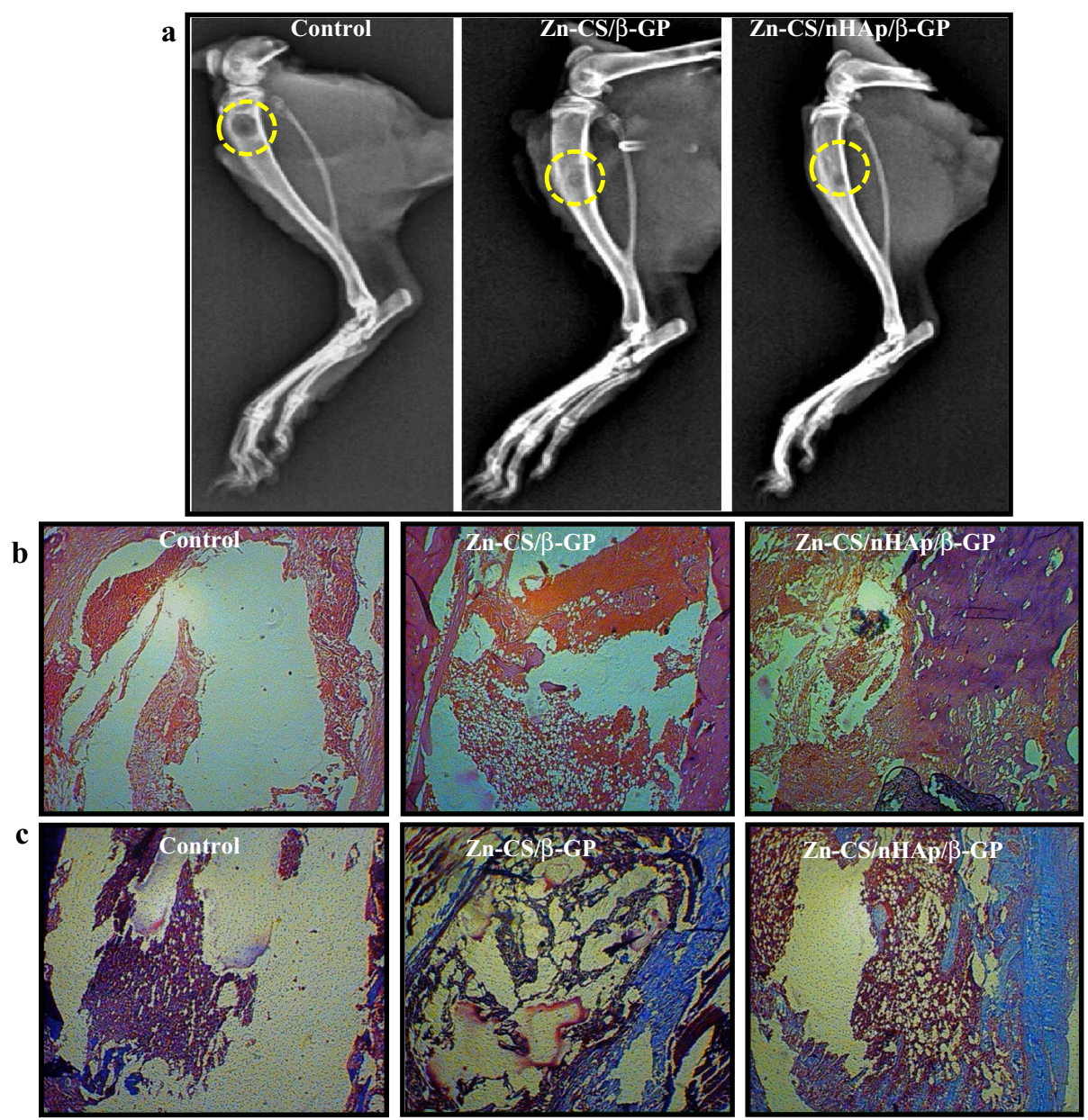

Figure $8 \mathrm{Effect}$ of $\mathrm{Zn}-\mathrm{CS} / \mathrm{nHAp} / \beta$-GP hydrogel on bone healing in vivo. a Radiographic images of the rat tibial defects obtained 2 weeks after they were filled with $\mathrm{Zn}-\mathrm{CS} / \beta-\mathrm{GP}$ hydrogel or $\mathrm{Zn}-\mathrm{CS} / \mathrm{nHAp} / \beta$-GP hydrogel. $\mathbf{b}$ and $\mathbf{c}$ represent hematoxylin and eosin staining and collagen staining of the implants, respectively. Closure of the drill hole, formation of new bone, and deposition of collagen were seen in $\mathrm{Zn}-\mathrm{CS} / \mathrm{nHAp} / \beta$-GP-treated animals. Dotted yellow circle indicates the drill hole defect and subsequent closure in hydrogel-treated animals. Purple color-stained areas indicate the formation of bone, and blue-colored areas depict the deposited collagen.

"conditioned medium", was taken and added at different volumes $(25,50,100,200,300$, and $400 \mu \mathrm{L})$ to the wells containing cells. Triton X-100 (0.1\%) served as a positive control. Cells seeded into the wells with normal medium and incubated for $24 \mathrm{~h}$ served as negative controls. The medium was carefully aspirated from the wells, and $200 \mu \mathrm{L}$ of $0.05 \%$ MTT solution was added to each well and incubated for another hour at $37^{\circ} \mathrm{C}$. DMSO was used to dissolve the formazan crystals formed, and the optical densities (OD) were measured using a spectrophotometer (ULTRA SPEC 2100 pro; Amersham Life Sciences, USA) at $570 \mathrm{~nm}$.

\section{Cell morphology evaluation}

$\mathrm{Zn}-\mathrm{CS} / \beta-\mathrm{GP}$ and $\mathrm{Zn}-\mathrm{CS} / \beta-\mathrm{GP} / \mathrm{nHAp}$ hydrogels were UV-treated for $2 \mathrm{~h}$. Approximately $2 \times 10^{5} \mathrm{mMSCs}$ were seeded onto the hydrogels and incubated for 4 days. The medium was changed once every 2 days. After 4 days of incubation, the medium was removed and the cells were washed with ice-cold $1 \times$ PBS. Ten milligrams of fluorescein diacetate (FDA) (Sigma Aldrich) was weighed and dissolved in $10 \mathrm{~mL}$ of acetone, which served as the stock solution. A working solution was prepared freshly by mixing $30 \mu \mathrm{L}$ of the stock solution with $10 \mathrm{~mL}$ of PBS. One milliliter of this working solution was added onto the films in each well and incubated for $15 \mathrm{~min}$ at $37^{\circ} \mathrm{C}$ in the dark [51]. Cells were observed under a fluorescent microscope with $4 \times$ and $10 \times$ objectives.

\section{Western blot analysis}

mMSCs were grown in normal or osteogenic medium with $\mathrm{Zn}-\mathrm{CS} / \beta-\mathrm{GP}$ or $\mathrm{Zn}-\mathrm{CS} / \beta-\mathrm{GP} / \mathrm{nHAp}$ hydrogels for 
different time periods. The cells were then washed with cold phosphate-buffered saline (PBS), and whole cell lysates were prepared. Twenty micrograms of proteins was resolved using $12 \%$ sodium dodecyl sulfate-polyacrylamide gel electrophoresis (SDS-PAGE) and transferred to polyvinylidene difluoride (PVDF) membranes by electroblotting. The membranes were blocked with $5 \%$ non-fat milk powder (BioRad) and incubated overnight with a primary antibody at $4^{\circ} \mathrm{C}$. The membranes were probed with secondary antibodies conjugated with horseradish peroxidase (HRP). Finally, the bands were visualized by adding Super Signal West Dura Extended Duration Substrate (Thermo Scientific) according to the manufacturer's instructions. The images obtained were used for quantification with the ImageJ software, as described previously [52]. Mouse monoclonal Runx2 $(1: 1,000)$ antibodies, Cdk2 (1:1,000) antibodies, and secondary antibodies conjugated with HRP were obtained from Santa Cruz Biotechnology. Cdk2 antibodies served as internal loading controls.

\section{Real-time RT-PCR analysis}

mMSCs were grown for different time periods in normal or osteogenic medium conditioned with $\mathrm{Zn}-\mathrm{CS} / \beta-\mathrm{GP}$ or $\mathrm{Zn}-\mathrm{CS} / \beta-\mathrm{GP} / \mathrm{nHAp}$ hydrogels. Total RNA was isolated using the Trizol method (Invitrogen) according to the manufacturer's instructions. cDNA synthesis was carried out with $1 \mu \mathrm{g}$ of total RNA from each sample using the GeNei AMV RT-PCR kit according to the manufacturer's protocol. SYBR reagent (BioRad) was used for real-time RT-PCR with mouse-specific oligonucleotide primers, as shown in Table 2. Relative mRNA expression was calculated by using the $\Delta \Delta \mathrm{Ct}$ method of relative quantification [34].

\section{In vivo examination of bone formation in drill hole defects in rat tibia}

Male Wistar rats (3 months old) weighing 200-250 g were kept in a room with light (12 h light-dark cycle)

Table 2 Primer sequences used for real-time RT-PCR analysis (F: forward; R: reverse)

\begin{tabular}{ll}
\hline Gene & Primer sequence (forward/reverse) \\
\hline Runx2 & 5'CGCCTCACAAACAACCACAG 3' (F) \\
ALP & 5'TCACTGTGCTGAGAGGCTG 3' (R) \\
& 5'TTGTGCCAGAGAAAGAGAGAGA 3' (F) \\
COL-1 & 5'GTTTCAGGGCATTTTCAAGGT 3' (R) \\
& 5'TAACCCCCTCCCCAGCCACAAA 3' (F) \\
OC & 5'TTCCTCTTGGCGTGCGTCA 3' (R) \\
& 5'ATGGCTTGAAGACCGCCTAC 3' (F) \\
GAPDH & 5'AGGGCAGAGAGAGAGGACAG 3' (R) \\
& 5'GAGAGACCCCACTTGCTGCCA 3'(F) \\
\hline
\end{tabular}

at a controlled temperature. The procedure for creating drill hole defects was approved by the animal ethical committee, Kovai Medical College and Hospital, Coimbatore, India. Rats were divided into three groups ( $n=6$ in each group): (1) control, (2) Zn-CS/ $\beta-G P$, and (3) $\mathrm{Zn}-\mathrm{CS} / \beta-\mathrm{GP} / \mathrm{nHAp}$. The rats were anesthetized with $10 \%$ ketamine and $2 \%$ xylazine $(1: 1,0.1 \mathrm{~mL} / 100 \mathrm{~g}$ body weight, i.m.) and subjected to perforation of the right tibia by using a dental drill (diameter, $3 \mathrm{~mm}$ ) under constant saline irrigation $(0.9 \% \mathrm{NaCl})$. The defects were entirely filled with each of the hydrogels in the respective experimental groups. The defects in control animals were left unfilled. After 14 days, the animals were sacrificed under anesthesia and the tibiae were removed and radiographed. The tibiae were then fixed in neutral $10 \%$ buffered formalin for $48 \mathrm{~h}$ at room temperature. The specimens were embedded in paraffin after decalcification, sectioned at a thickness of $6 \mu \mathrm{m}$, and examined with H\&E staining and collagen (Masson's trichrome) staining.

\section{Statistical analysis}

All experiments were performed in triplicates and the results have been expressed as the mean \pm standard deviation (S.D.) Statistical significance was calculated by ANOVA and Student's $t$ test analyses. A $p$ value of lower than 0.05 was considered to be statistically significant.

\section{Abbreviations}

3D: three-dimensional; Zn: zinc; CS: chitosan; nHAp: nanohydroxyapatite; $\beta$-GP: beta-glycerophosphate; SEM: scanning electron microscopy; EDX: energy dispersive spectroscopy; FTIR: Fourier transform infrared spectroscopy; XRD: X-ray diffraction; MTT: (3-(4,5-dimethylthiazol-2-yl)-2,5-diphenyltetrazolium bromide); RT-PCR: reverse transcriptase polymerase chain reaction; ECM: extracellular matrix; GAGs: glycosaminoglycans; ALP: alkaline phosphatase; hBMSCs: human bone marrow stem cells; JCPDS: joint committee on powder diffraction standards; SBF: simulated body fluid; mMSCs: mouse mesenchymal stem cells; COL-1: type-I collagen; OC: osteocalcin; FDA: fluorescein diacetate; SDS-PAGE: sodium dodecyl sulfate-polyacrylamide gel electrophoresis; PVDF: polyvinylidene fluoride; HRP: horseradish peroxidase.

\section{Authors' contributions}

SD performed all experiments except for the animal studies. SS carried out the animal experiments. SD and SS wrote the manuscript. NS planned all experiments and provided the facilities necessary for the completion of this work. SD, SS, TPS, and NS analyzed and verified the experimental data. All authors have read and approved the final manuscript.

\section{Author details}

${ }^{1}$ Department of Biotechnology, School of Bioengineering, SRM University, Kattankulathur 603203, Tamil Nadu, India. ${ }^{2}$ Bioproducts Laboratory, Central Leather Research Institute, Chennai 600 020, Tamil Nadu, India.

\section{Acknowledgements}

We thank Dr. M. Michael Aruldhas from the University of Madras for providing the fluorescent microscope facility. We also thank the Nanotechnology Research Centre at SRM University for providing the SEM facility. This work was supported in part by SRM University and Council for Science and Industrial Research, India [Grant No. 37 (1574)/12/EMR-II to N. S]. 


\section{Compliance with ethical guidelines}

\section{Competing interests}

The authors declared that they have no competing interests.

Received: 19 January 2015 Accepted: 19 May 2015

Published online: 12 June 2015

\section{References}

1. Arrington ED, Smith WJ, Chambers HG, Bucknell AL, Davino NA (1996) Complications of iliac crest bone graft harvesting. Clin Orthop Relat Res 329:300-309

2. Schaaf H, Lendeckel S, Howaldt HP, Streckbein P (2010) Donor site morbidity after bone harvesting from the anterior iliac crest. Oral Surg Oral Med Oral Pathol Oral Radiol Endod 109:52-58

3. Drury JL, Mooney DJ (2003) Hydrogels for tissue engineering: scaffold design variables and applications. Biomaterials 24:4337-4351

4. Lee KY, Mooney DJ (2001) Hydrogels for tissue engineering. Chem Rev 101:1869-1880

5. Fedorovich NE, Alblas J, De Wijn JR, Hennink WE, Verbout AJ, Dhert WJ (2007) Hydrogels as extracellular matrices for skeletal tissue engineering: state-of-the-art and novel application in organ printing. Tissue Eng 13:1905-1925

6. Mano JF (2008) Stimuli-responsive polymeric systems for biomedical applications. Adv Eng Mater 10:515-527

7. Huang Z, Tian J, Yu B, Xu Y, Feng Q (2009) A bone-like nanohydroxyapatite/collagen loaded injectable scaffold. Biomed Mater. doi:10.1088/1748-6041/4/5/055005

8. Martins AM, Alves CM, Kasper FK, Mikos AG, Reis RL (2010) Responsive and in situ-forming chitosan scaffolds for bone tissue engineering applications: an overview of the last decade. J Mater Chem 20:1638-1645

9. Jayakumar R, Prabaharan M, Nair SV, Tokura S, Tamura H, Selvamurugan N (2010) Novel carboxymethyl derivatives of chitin and chitosan materials and their biomedical applications. Prog Mater Sci 55:675-709

10. Knapczyk J, Krowczynski L, Krzck J, Brzeski M, Nirnberg E, Schenk D et al (1989) Requirements of chitosan for pharmaceutical and biomedical applications. In: Skjåk-Braek G, Anthonsen T, Sandford PA (eds) Chitin and Chitosan: sources, chemistry, biochemistry, physical properties and applications. Elsevier, London, pp 657-663

11. Hirano S, Seino H, Akiyama I, Nonaka I (1990) Chitosan: a biocompatible material for oral and intravenous administration. In: Gebelein CG, Dunn RL (eds) Progress in biomedical polymers. Plenum Press, New York, pp 283-90

12. Muzzarelli RAA (1997) Human enzymatic activities related to the therapeutic administration of chitin derivatives. Cell Mol Life Sci 53:131-140

13. Raafat D, Sahl HG (2009) Chitosan and its antimicrobial potential—a critical literature survey. Microb Biotechnol 2:186-201

14. Freier T, Koh HS, Kazazian K, Shoichet MS (2005) Controlling cell adhesion and degradation of chitosan films by N-acetylation. Biomaterials 26:5872-5878

15. Madihally SV, Matthew HWT (1999) Porous chitosan scaffolds for tissue engineering. Biomaterials 20:1133-1142

16. Varma AJ, Deshpande SV, Kennedy JF (2004) Metal complexation by chitosan and its derivatives: a review. Carbohydr Pol. 55:77-93

17. Rohindra R, Nand AV, Khurma JR (2004) Swelling properties of chitosan hydrogels. South Pac J Nat App Sci. 22:32-35

18. Qiu Y, Park K (2001) Environment-sensitive hydrogels for drug delivery. Adv Drug Deliv Rev 53:321-339

19. Chvapil M (1973) New aspects in the biological role of zinc: a stabilizer of macromolecules and biological membranes. Life Sci 13:1041-1049

20. Yamaguchi M, Weitzmann MN (2011) Zinc stimulates osteoblastogenesis and suppresses osteoclastogenesis by antagonizing NF-кB activation. Mol Cell Biochem 355:179-186

21. Hershfinkel M, Moran A, Grossman N, Sekler J (2001) A zinc-sensing receptor triggers the release of intracellular $\mathrm{Ca} 2+$ and regulates ion transport. Proc Natl Acad Sci USA 20:11749-11754

22. Tripathi A, Saravanan S, Pattnaik S, Moorthi A, Partridge NC, Selvamurugan N (2012) Bio-composite scaffolds containing chitosan/nanohydroxyapatite/nano-copper-zinc for bone tissue engineering. Int J Biol Macromol 50:294-299
23. Zhou H, Lee J (2011) Nanoscale hydroxyapatite particles for bone tissue engineering. Acta Biomater 7:2769-2781

24. Webster TJ, Ergun C, Doremus RH, Siegel RW, Bizios R (2000) Specific proteins mediate enhanced osteoblast adhesion on nanophase ceramics. J Biomed Mat Res 51:475-483

25. Gleeson JP, Plunkett NA (2010) Addition of hydroxyapatite improves stiffness, interconnectivity and osteogenic potential of a highly porous collagen-based scaffold for bone tissue regeneration. Eur Cell Mater 20:218-230

26. Chung H, Golub EE, Forbes E, Tokuoka T, Shapiro IM (1992) Mechanism of action of beta-glycerophosphate on bone cell mineralization. Calcif Tissue Int 51:305-311

27. Chang YL, Stanford CM, Keller JC (2000) Calcium and phosphate supplementation promotes bone cell mineralization: implications for hydroxyapatite (HA)-enhanced bone formation. J Biomed Mat Res $52: 270-278$

28. Wang L, Stegemann JP (2010) Thermogelling chitosan and collagen composite hydrogels initiated with $\beta$-glycerophosphate for bone tissue engineering. Biomaterials 31:3976-3985

29. Cho J, Heuzey MC, Begin A, Carreau PJ (2005) Physical gelation of chitosan in the presence of $\beta$-glycerophosphate: the effect of temperature. Biomacromolecules 6:3267-3275

30. Lavertu M, Filion D, Buschmann MD (2008) Heat-induced transfer of protons from chitosan to glycerol phosphate produces chitosan precipitation and gelation. Biomacromolecules 79:640-650

31. Chenite M, Buschmann D, Wang D, Chaput C, Kandani N (2001) Rheological characterization of thermogelling chitosan/glycerol phosphate solutions. Carbohydr Polym 46:39-47

32. Huang J, Best SM, Bonfield W, Brooks RA, Rushton N, Jayasinghe SN et al (2004) In vitro assessment of the biological response to nano-sized hydroxyapatite. J Mater Sci Mater Med 15:441-445

33. Cerroni L, Filocamo R, Fabbri M, Piconi C, Caropreso S, Condo SG (2002) Growth of osteoblast-like cells on porous hydroxyapatite ceramics: an in vitro study. Biomol Eng 19:119-124

34. Zhou H, Lee J (2011) Nanoscale hydroxyapatite particles for bone tissue engineering. Acta Biomater 7:2762-2781

35. Salehi R, Arami M, Mahmoodi NM, Bahrami H, Khorramfar S (2010) Novel biocompatible composite (chitosan-zinc oxide nanoparticle): preparation, characterization and dye adsorption properties. Colloids Surf B Biointerfaces 80:86-93

36. Wang X, Du Y, Fan L, Liu H, Hu Y (2005) Chitosan-metal complexes as antimicrobial agent: synthesis, characterization and structure-activity study. Polym Bull 55:105-113

37. Han JK, Song HY, Saito F, Lee BT (2006) Synthesis of high purity nanosized hydroxyapatite powder by microwave-hydrothermal method. Mater Chem Phy 99:235-239

38. Balamurugan A, Michel J, Faure J, Benhayoune H, Wortham L, Sockalingum G et al (2006) Synthesis and structural analysis of sol gel derived stoichiometric monophasic hydroxyapatite. Ceram Silik 50:27-31

39. Pawlak A, Mucha M (2003) Thermogravimetric and FTIR studies of chitosan blends. Thermochim Acta 396:153-166

40. Peter M, Ganesh N, Selvamurugan N, Nair SV, Furuike T, Tamura H et al (2010) Preparation and characterization of chitosan-gelatin/nanohydroxyapatite composite scaffolds for tissue engineering applications. Carbohydr Poly 80:687-694

41. Ji C, Khademhosseini A, Dehghani F (2011) Enhancing cell penetration and proliferation in chitosan hydrogels for tissue engineering applications. Biomaterials 32:9719-9729

42. Ren D, Yi H, Wang W, Ma X (2005) The enzymatic degradation and swelling properties of chitosan matrices with different degrees of $\mathrm{N}$-acetylation. Carbohydr Res 340:2403-2410

43. Lord MS, Foss M, Besenbacher F (2010) Influence of nanoscale surface topography on protein adsorption and cellular response. Nano Today 5:66-78

44. Harada H, Tagashira S, Fujiwara M, Ogawa S, Katsumata T, Yamaguchi A et al (1999) Cbfa1 isoforms exert functional differences in osteoblast differentiation. J Biol Chem 274:6972-6978

45. Bellows CG, Aubin JE, Heersche JNM (1991) Initiation and progression of mineralization of bone nodules formed in vitro: the role of alkaline phosphatase and organic phosphate. Bone Min 14:27-40 
46. Nudelman F, Pieterse K, George A, Bomans PH, Friedrich $H$, Brylka $L$ J et al (2010) The role of collagen in bone apatite formation in the presence of hydroxyapatite nucleation inhibitors. Nat Mater 9:1004-1009

47. Boskey AL, Gadaleta S, Gundberg C, Doty SB, Ducy P, Karsenty G (1998) Fourier transform infrared microspectroscopic analysis of bones of osteocalcin-deficient mice provides insight into the function of osteocalcin. Bone 23:187-196

48. Niranjan R, Koushik C, Saravanan S, Moorthi A, Vairamani M, Selvamurugan N (2012) A novel injectable temperature-sensitive zinc doped chitosan/ $\beta$-glycerophosphate hydrogel for bone tissue engineering. Int J Biol Macromol 54:24-29

49. Pattnaik S, Nethala S, Tripathi A, Saravanan S, Moorthi A, Selvamurugan N (2011) Chitosan scaffolds containing silicon dioxide and zirconia nano particles for bone tissue engineering. Int J Biol Macromol 49:1167-1172
50. Jalota S, Bhaduri SB, Tas AC (2008) Using a synthetic body fluid (SBF) solution of $27 \mathrm{mM} \mathrm{HCO}_{3}{ }^{-}$to make bone substitutes more osteointegrative. Mater Sci Eng C 28:129-140

51. Moller B, Terheyden H, Açil Y, Purcz NM, Hertrampf $K$, Tabakov A et al (2012) A comparison of biocompatibility and osseointegration of ceramic and titanium implants: an in vivo and in vitro study. Int J Oral Maxillofac Surg 41:638-645

52. Vimalraj S, Partridge NC, Selvamurugan N (2014) A positive role of microRNA-15b on regulation of osteoblast differentiation. J Cell Physiol 229:1236-1244

\section{Submit your next manuscript to BioMed Central} and take full advantage of:

- Convenient online submission

- Thorough peer review

- No space constraints or color figure charges

- Immediate publication on acceptance

- Inclusion in PubMed, CAS, Scopus and Google Scholar

- Research which is freely available for redistribution

Submit your manuscript at

www.biomedcentral.com/submit

C Biomed Central 